slight blowing murmur, so protracted, however, as to render this longer by one-half than the first sound. There is no vascular murmur observable in the back of the thorax, save a slight bruit de souffet to the left of the first dorsal vertebra. The murmur described as existing to the right of the sternum, is andible in both carotid arteries, and most so in that of the right side; it is also heard between the sterno-clavicular articulations.

I had the patient admitted into the wards of the institution at which he had applied for relief (the Wolverhampton Dispensary) on the $26 \mathrm{th}$ of $\mathbf{J u l y}, 1848$; but he left at his own request at the expiration of three days. The diagnosis then made was aneurism of thoracic aorta, with hypertrophy of left ventricle. IIe came to see me at intervals until the 21 st of October, 1848, during which period there was little change observable in the physical signs, save that the inequality in the duration of the two cardiac sounds had to a great extent disappeared. He was enjoined to avoid all active pursuits as far as possible, with all excesses in diet, and was ordered a mixture containing tincture of digitalis and sulphate of magnesia.

From October the 21st, 1848, until the time of his decease, May 16 th, 1851, he was entirely lost sight of, and the above history and observations are copied from notes made by me at the time.

Post mortem appearances.-An examination of the contents of the thorax was made on the night of the patient's death. The left ventricle of the heart was found to be greatly enlarged, the corresponding cavity on the opposite side remaining of the natural dimensions. The wall of the dilated ventricle was exactly one inch in thickness, measured near the septum ventriculorum; and the weight of the entire heart amounted to two pounds twelve ounces. The division between two of the aortic sigmoid valves was destroyed, and the two fused, as it were, into one, so that an irregular, buttonholelooking orifice remained. The other valves of the heart were healthy. The aorta was greatly dilated from immediately above the situation of the semilunar valves to the giving off of the brachio-cephalic trunk. An inch above the aortic valves, on the posterior aspect of the vessel, there was an aneurismal pouch, about the size and shape of a chesnut. There was no rupture of any of the coats of the aorta, but its inner surface was studded with cartilaginous-looking nodules. The pericardium was not adherent, but traces of former inflammation of that membrane were shown by the presence of two white patches situated upon its visceral layer, upon the left ventricle, the larger of these being two inches in length. They were not raised above the surface of the heart. Each of the lungs exhibited marks of extensive recent inflammation, the patient having succumbed to an attack of pneumonia after a short illness.

Remarks.-It must ever add to its interest upon our minds, when, after having lost sight of a case of disease for many months, or even for years, the subject of it is again unexpectedly presented to our observation, and the notes and remarks registered and made upon previous occasions are rendered capable of being compared, and the accuracy of the views then taken verified, as was enabled to be done in the instance under consideration.

The complaint under which this patient laboured was probably referred to its true cınse by the sufferer himself-that of mechanical injury, coupled with a life passed in laborious exertion. A very parallel instance is thus related in the graphic words of Dr. Latham:-

"A man passing through Spa-fields one night was unmercifully beaten and plundered; and thrown into a ditch, and left to die. Die, however, he did not, but lay there he knew not how long; for he was insensible. The next day he was found, and taken home. He was disabled by the bruises he had received, and by palpitation of the heart and dyspncea, which he had never complained of before; and was never again able to return to his ordinary occupation. After some months he was admitted into St. Bartholomew's Hospital, dropsical, and bearing all the symptoms which denote hypertrophy and dilatation of the heart. He soon died, and his heart was found of a size which was almost incredible. All its muscular substance was enormously amplified, and all its cavities enormously dilated; its pericardium, and lining membrane, and valves free from disease." ("Lectures on Diseases of the Heart," vol. ii. p. 205.)

It has been proved, in various instances, that excessive muscular exertion is capable of occasioning immediate injury to the mechanism of the heart. Thus in Dr. Latham's admirable work, is a case communicated by Dr. Bence Jones, $\mathbf{n}$ which one of the septa of the aortic valves " was torn away from its attachments, and thus two of its pouches were reduced to a single irregular one." When acting as house-surgeon to University College Hospital, London, an instance, occasioned in a similar manner to the above, was shown to me by $\mathrm{Mr}$. Mercer, of Deal; and the precise nature of the disorder has since been ascertained and described by my friend Dr.R. Quain, under whose care the man afterwards was placed. He lived for nearly two years (this was in 1843), and after his death, Dr. Quain had an opportunity of examining the organs contained within the thorax, when it was found that "all the cavities of the heart were enlarged and filled with blood. The arch of the aorta was somewhat dilated; the heart weighed twenty-two ounces. The chief disease was found at the entrance of the aorta; here it was noticed that the conjoined attachments of two of the valves to the aorta had been separated from the wall of that vessel, and thus those valves were allowed to drop below the level of the third, which retained its connexions." When I saw the patient, the character of the lesion was plainly evident from the loud regurgitant aortic murmur which existed, and which was strongly audible, even along the course of the femoral arteries. This case, with other similar ones, was submitted by Dr. Quain to the Pathological Society of London, October 20th, 1846; and they are all recorded in the Monthly Journal of Mredical Science for December of that year.

The weight of the heart in the case now under consideration, in place of being eight ounces and a half, as is stated by Dr. Clendinning to be the average in persons aged between thirty and fifty years, amounted to two pounds twelve ounces. It is to be regretted that a microscopical examination of the morbid deposit observed in the aorta was not nade; but owing to some carelessness, the parts were mislaid before I had time to institute such an investigation.

In respect to the physical signs observable during life, these were snch as to admit of no doubt as to the nature and seat of the disease. The localization of these signs on the right of the sternum, at the seat of articulation of the second and third ribs, was sufficient to indicate that the ascending aorta was the part implicated. Besides the dulness on pereussion and the impulse, the presence of two morbid sounds, neither of which existed prominently over the heart itself, (though there were most unequivocal signs of great disease of that organ, ) showed that the origin of these must be referred to something extraneous to the great organ of the circulation. The natural resonance on percussion of the right side of the thorax (save over the situation before indicated), went to prove that there was no tuberculization of the lung, since in that case the dulness would probably have extended up into the acromial angle, the proper stethoscopic corner, as it is called by Dr. C. J. B. Williams ("Library of Practical Medicine," vol. iii. p. 176). The necropsy demonstrated that there were no tubercles deposited in the lungs, and thus added another to the instances tending to show that pulmonary tuberculosis and aneurism are not frequent concomitants. The hæmoptysis which had occurred three years previously, must be attributed to some other cause than the disease now described; perhaps to that given by the patient-viz., unusual bodily toil, occasioning rupture of some of the pulmonary tissues.

August, 1852.

\section{REMOVAL OF A CARIOUS OS CALCIS}

Bx A. G. FIELD, M.R.C.S., L.S.A., SURGEON TO THE ROYAL SEA-BATHING INFIRMARY.

CASE.-Edward E_- aged seventeen, was admitted to the Royal Sea-bathing Infirmary, with caries of the left os calcis. There was an ulcer about an inch behind each malleolus as large as the top of the finger; through these a probe could be passed directly on to so large an extent of diseased bone as to leave little doubt that the whole was affected; its removal was therefore determined on. An abscess formed in the back of the heel six days before the operation, but this was opened inmediately fluctuation could be detected, and the parts around it recovered sufficiently to form a flap.

Operation-On the $26 \mathrm{th}$ of $\mathrm{July}$, with the assistance of Messrs. Hoffman, Hunter, and Price, (consulting-surgeons to the Infirmary,) I proceeded with the operation in the following manner:- The patient being placed well under the influence of chloroform, the point of a scalpel was passed through the internal ulcer down to the bone, carried downwards and forwards, across the sole, backwards and upwards to the ulcer described as situated behind the outer ankle; this incision was behind the posterior tibial artery and nerve. 
Another incision of about two inches in extent was made to pass from the convexity of this directly forwards on quite the outer part of the sole, over the calcaneo-cuboid articulation. A flap was then dissected from the heel, the tendo-Achillis divided, and the whole back part of the calcis exposed. Lateral flaps were next dissected back, the artery and nerve being carefully preserved while making the inner one. Thus the plantar, external, and internal surfaces of the bone were exposed. The bone was next grasped in order to steady and use it as a lever, while a stout, narrow-bladed knife, made for the purpose by Messrs. Ferguson, was introduced between the calcis and astragalus, to divide the interosseous ligament; this done, the anterior connexions of the bone were divided in a similar manner, and the excision completed. Very little blood was lost, and no ligature was required.

Three hours after the operation, all oozing having ceased, the flaps were brought together with two sutures and a few strips of isinglass plaster, a compress was placed over the heel, and secured by a roller which extended to the knee. On the fourth day the dressings were removed, and almost complete union was found to have taken place between the cut surfaces.

Remarks.-In performing the above operation, I adopted the plan recommended by $\mathrm{Mr}$. Guthrie in a lecture recorded in a recent number of THE LANCET, excepting that I commenced my incision further back, and exposed the calcaneo-cuboid articulation by means of a second cut. I was induced to do this by the situation of sinuses which I wished to include, and still more by my desire to preserve the posterior tibial artery; for though doubtless the foot would have received a sufficient supply of blood from other sources, there could be no disadvantage in attempting the preservation of this vessel; its division during the operation would materially delay its performance; and further, its preservation would allow of more pressure being subsequently made with the bandage without fear of sloughing. In order to expose the anterior part of the calcaneum, a second incision was carried forwards from the first, quite in the outer part of the sole, to avoid the external plantar artery; this rendered it unnecessary to have so large a posterior flap, which was, in consequence, more easily dissected back. The second incision was also useful in allowing the parts to adapt themselves more perfectly to the hollow caused by the removal of the bone.

Margate, August, 1852.

\section{A CONTRIBUTION TO CLINICAL MIDWIFERY.}

\section{By N. J. HIGHMORE, M.D., M.R.C.S., Bradford.}

A. B-, aged thirty-six, sent for me at seven o'clock on the morning of the 29th of January, she being in labour with her first child. She stated that her pains had commenced at midnight, and continued gradually inereasing in frequency and severity. They now occur at intervals of about five minutes; the bowels have been twice purged, and the urine is passed frequently and without difficulty. On examination, I felt the head of the child distinctly through the uterine parietes; and after a short time I left.

At half-past nine I was again summoned; the pains were then rather more frequent, but $I$ found that $I$ was unable to detect the os or cervix uteri, although the vagina was relaxed, and the uterus descended low down with each pain, feeling like a smooth, globular mass, bounded all around by the vaginal cul-de-sac.

I again called at half-past one, when the symptoms remaining as before, $I$ informed one of the persons present of the nature of the case, gave a dose of laudanum, to allay excessive uterine action and favour relaxation, and again left, thinking that if agglutination existed, the continuous pain would develop the os.

At half-past four I again visited my patient, and found that although the pains were almost constant, and very severe, not the slightest trace of the uterine orifice existed. I therefore stated the nature of the difficulty to the family, and requested that my friend Dr. Morgan might be called in to consult with me.

At his arrival, shortly after six o'clock, on examination, the occluded os uteri was found to have yielded, and was dilated almost to the size of a half-crown; and so rapidly did the labour progress, that she was delivered at ten minutes before seven, of a living female child. The placenta was adherent, and had to be removed; it was very soft and friable, breaking upon the slightest pressure, and having precisely the feeling and consistence of clotted blood. The mother made a good revery, and both she and the infant are now well.

Remarks.-The patient whose case I have narrated, has, since her marriage and during gestation, enjoyed good health, but, previously, was for years in a very delicate state, suffering from anæmia, general debility, dyspepsia, pain in the back, scanty, painful menstruation, and leucorrhoea; the connexion between which symptoms and the history of her labour, forming, I think, a very perfect and interesting illustration of one branch of uterine pathology.

Bradford, Wilts, 1852 .

\section{A Alirror}

OF THE PRACTICE OF

\section{MEDICINE AND SURGERY IN THE \\ HOSPITALS OF LONDON.}

Nulla est alia pro certo noscendi via, nisi quam plurimas et morborum, et tionum historias, tum aliorum proprias, collectas habere et inter se comparare.-Morgagnr. De Sed. et Caus. Morb., lib. 14. Proomium.

\section{ST. BARTHOLOMEW'S HOSPITAL.}

Epidemic of Carbuncular Inflammation of the Lip.

(Cases under the care of Mr. STANLEY and Mr. Llord.)

AN epidemic of carbuncular inflammation of the upper lip has been reigning for some time past, and the disease has proved in some instances extremely severe, and even fatal. Cases of this affection have occurred in various hospitals, but it would appear that by far the larger portion have been admitted into this institution. It is worthy of remark that the number of cases of common carbuncle is not in the least diminished by the above-mentioned epidemic-indeed, they seem to have greatly increased. The size of the sores is here and there enormous (as large as a dessert-plate), and the fact obtrudes itself upon the observer, that there is now reigning one and the same epidemic, attacking either the nape of the neck or the upper lip.

It is particularly to the latter affection that we wish to draw attention, for we are not aware that it has been described by surgical writers. Indeed, when it was first observed at St. Bartholomew's Hospital, the general impression was, that it depended on some local irritation, or was the result of some noxious influence connected with the patient's trade. (See The LanceT, vol. ii. 1851, p. 104). But no such idea can now be entertained, for the numerous cases which present themselves all point to a generally-diffused epidemic action. Of what nature the poison may be, is, however, somewhat difficult to discover; but one fact should nevertheless be noticed-viz., the recurrence of the epidemic at the hot season of the year, and also the circumstance that the cases have been far more numerous this very hot summer than they were last year, when the temperature was uniformly lower.

It would be interesting to ascertain whether cases of this kind have been at all observed in private practice among the middle and higher classes of society, in order to determine whether the great heat, combined with the effects of unhealthy dwellings or trades, is the chief agent in the production of the pathological phenomena to which we are alluding.

We know of one case, in which the subject was a surgeon, whose symptoms were very severe. The patient was under the care of Mr. Wormald, and recovered completely. Free incisions and stimulants formed the principal features of the treatment.

The cases have been so numerous at this hospital, that we shall not attempt to particularize them,-indeed, the symptoms were very much of the same nature in all instances, the difference lying principally in the more or less intensity. The principal phenomenon presented is an enormous swelling of the upper lip, arising gradually from a pustule, which springs up at some part of the upper lip. The heat, pain, and redness do not keep pace with the odema, which latter is the most striking symptom. This is generally carried so far, that the whole face becomes frightfully swollen, as is seen in the worst cases of erysipelas. Such distention and infiltration must necessarily be followed by slonghing of the cellular tissue; and this change is made very evident by the aspect of the parts after the incisions which are generally made through the 